\title{
IMPLEMENTASI DATA MINING PADA PENJUALAN PRODUK DI CV CAHAYA SETYA MENGGUNAKAN ALGORITMA FP-GROWTH
}

\author{
Wahyu Nur Setyo ${ }^{1}$, Sukma Wardhana ${ }^{2}$ \\ Jurusan Teknik Informatika, Fakultas Ilmu Komputer, Universitas Mercu Buana ${ }^{1,2}$ \\ Jl. Raya Meruya Selatan, Kembangan, Jakarta, 11650 \\ E-mail :wahyunursetyo17@gmail.com, sukma@mercubuana.ac.id
}

\begin{abstract}
At this time the growth of data occurs rapidly and fast long with the use of computer systems in various transactions. But this increasingly large volume of data has no meaning if it is not processed into a knowledge which can be done by data mining. Association rule or what is known as market based analysis is one type of data mining implementation. This study aims to find patterns of transaction data in the CV Cahaya Setya retail industry by using aFrequent Pattern Growth algorithm also known as FP-Growth algorithm. FP-Growth aims to find all the set items that can be retrieved (often found) from the transaction database as efficiently as possible. The results of this study show that the pattern on the database of consumer transactions at CV Cahaya Setya retail industry the FP-Growth algorithm and implement it in the application
\end{abstract}

Keywords: Data mining, retail industry, association rule, FP-growth algorithm

\begin{abstract}
ABSTRAK
Pada saat ini pertumbuhan data terjadi dengan cepat dan pesat seiring dengan penggunaan sistem komputer dalam berbagai transaksi. Tetapi volume data yang semakin besar ini tidak memiliki arti jika tidak diolah menjadi sebuah pengetahuan dimana hal ini dilakukan oleh data mining. Association rule atau yang dikenal sebagai market based analysis merupakan salah satu tipe implementasi dari data mining. Beberapa penelitian telah dilakukan untuk mencari pola pada data transaksi dengan tipe implementasi association rule. Penelitian ini bertujuan untuk mencari pola dari data transaksi di industri retail yaitu pada CV Cahaya Setya dengan menggunakan algoritma Frequent Pattern Growth atau yang dikenal pula sebagai FP-Growth. FP-Growth bertujuan untuk menemukan semua itemset yang dapat diambil (yang sering ditemukan) dari basis data transaksi seefisien mungkin. Hasil penelitian ini memperlihatkan bahwa pola pada basis data transaksi konsumen pada industri retail yaitu pada CV Cahaya Setya dapat ditemukan dengan menggunakan algoritma FP-Growth kemudian mengimpelementasikannya pada aplikasi penjualan produk di $\mathrm{cv}$ cahaya setya menggunakan fp gwoth
\end{abstract}

Kata Kunci: data mining, market based analysis, association rule (aturan sosiasi), frequent pattern growth (FP-Growth), industri retail 


\section{PENDAHULUAN}

Pada saat ini industry perdagangan semakin berkembang dengan data transaksi yang meningkat jumlahnya setiap saat. Terhadap kondisi tersebut dibutuhkan sebuah metode atau teknik yang dapat mengubah hamparan data tersebut menjadi sebuah informasi atau pengetahuan (knowledge) yang bermanfaat untuk mendukung pengambilan keputusan dalam bisnis. Teknologi yang dapat digunakan untuk mewujudkannya adalah data mining. Proses pengolahan atas data dengan jumlah yang besar dengan menggunakan teknik dan metode yang beragam. Dari beberapa metode yang sering digunakan dalam teknologi data mining adalah metode asosiasi atau association rule mining. Di dalam bidang usaha distributor dan penjualan berbentuk retail, metode association rule mining ini lebih dikenal dengan istilah analisa keranjang belanja (market basket analysis).Analisa terhadap kecenderungan perilaku konsumen dalam melakukan belanja barang [1]. Sumber data dari market basket analysis antara lain dapat bersumber dari transaksi kartu kredit, kupon diskon, atau panggilan pesanan pelanggan. Market basket analysis umumnya dimanfaatkan sebagai titik awal pencarian pengetahuan dari suatu transaksi data ketika kita tidak mengetahui pola spesifik apa yang kita cari. Kebutuhan market basket analysis berawal dari keakuratan dan manfaat yang dihasilkannya dalam wujud aturan assosiasi (association rules), polapola dari data yang memiliki keterkaitan dalam basis data [2]. Sebagai perusahaan retail, CV Cahya Setya memiliki begitu banyak data transaksi, dengan tipe pembelian konsumen yang beragam. Membeli barang dengan jumlah satuan, ataupun membeli jenis barang secara berpasangan sesuai dengan kebutuhannya, contohnya membeli perangkat TV dan unit antenanya sekaligus ataupun membeli rak dengan atribut di dalamnya.banyaknya data transaksi penjualan tersebut semakin meningkat dengan setiap harinya. Terdapat beberapa algoritma yang dapat digunakan untuk menyusun Association rule Pada penelitian ini, penulis akan menggunakan algoritma FP-Growth, sebuah metode dalam data mining untuk mencari Frequent itemset Tanpa menggunakan candidate generation. Pembangunan data menggunakan struktur FP-Tree ntuk mengolah database transaksi [3]. FP-Growth menggunakan strategi divide-conquer sehingga algoritma ini hanya membutuhkan dua kali scanning database. Tujuan yang ingin di capai dalam penelitian ini antara lain adalah: (1) membuat fitur informasi penjualan CV Cahaya Setya dengan menerapkan metode data mining association rule mengunakan algoritma FP-Growth, (2) Membangun aplikasi berbasis desktop dengan menggunakan bahasa pemrograman PHP.

\section{METODE}

\section{A. Data Mining}

Kerangka proses data mining tersusun atas tiga tahapan, yaitu pengumpulan data (data collection), transformasi data (data transformation), dan analisis data (data analysis) [4].

\section{B. Algoritma Fp-Growth}

Frequent Pattern Growth (FP-Growth) adalah salah satu alternatif algoritma yang dapat digunakan untuk menentukan himpunan data yang paling sering muncul (frequent itemset) dalam sebuah kumpulan data [5]

Tahapan yang akan dilakukan untuk mendapatkan frequent itemset menggunakan algoritma FP-growth terbagi menjadi tiga langkah, antara lain:

a. Pembangkitan Conditional Pattern Base.

b. Pembangkitan Conditional FP- tree.

c. Pencarian frequent itemset.

\section{FP-TREE}

FP- TREE adalah struktur penyimpanan data yang dibangun dengan memetakan setiap data transaksi kedalam setiap lintasan tertentu. FP-tree digunakan dalam mencari pola frequent dangan batas ambang minimum support count $\xi$ dengan menggunakan algoritma FP-growth. Jika support 
dari pola tersebut tidak kurang dari konstanta $\xi$ (batas ambang minimum support) yang telah ditetapkan, maka pola tersebut dapat dikatakan sebagai frequent pattern (sering muncul). Adapun definisi dari FP-tree adalah [6]:

a. FP-tree terbentuk dari sebuah akar dengan label null;

b. Setiap simpul mengandung informasi: label item (jenis item yang direpresentasikan), support count (jumlah lintasan transakasi, dan pointer (penghubung simpul dengan label sama).

\section{HYPER TEXT MARKUP LANGUAGE (HTML)}

Hyper Text Mark Up Language merupakan bahasa asli dari www, yang telah menjadi bahasa standard untuk menampilkan data di internet Perkembangan html sangat pesat, saat ini versi terakhir dari html telah mencapai html [7].

\section{E. HYPERTEXT PROTOCOL (PHP)}

Pengertian PHP menurut php adalah bahasa pemrograman web berupa script yang dapat di integrasikan dengan HTML. PHP merupakan bahasa scripting yang open source dan digunakan untuk membuat website yang dinamis dan powerfull[8].

Pemrograman yang berjalan pada server memang banyak sekali, Setiap Program memiliki kelebihan dan kekurangan.Saat ini banyak website yang menggunakan PHP sebagai dasar pengolahan data.Beberapa keunggulan yang dimiliki program PHP (MADCOMS 2004) di antaranya adalah:

1) PHP memiliki tingkat akses yang lebih cepat

2) PHP memiliki tingkat lifecycle yang cepat sehingga selalu mengikuti perkembangan teknologi internet

3) PHP memiliki tingkat keamanan yang tinggi

4) PHP mampu berjalan di beberapa server yang ada misalnya Apache, Microsoft IIS, PWS, AOLserver, phttpd, fhttpd, dan xitami

5) PHP mampu berjalan di LINUX sebagai platform sistem operasi utama bagi PHP

6) PHP mendukung ke beberapa database yang sudah ada

7) PHP bersifat free atau gratis

\section{F. MYSQL}

MySQL adalah sebuah software yang Open Source, sehingga bebas dipakai dan dimodifikasi oleh semua orang. Setiap orang dapat mendownload MySQL dari internet dan menggunakannya tanpa harus membayar [9]. MySQL adalah sebuah perangkat lunak sistem manajemen basis data SQL Database Management System atau DBMS[10].

\section{HASIL DAN PEMBAHASAN}

\section{A. Hasil}

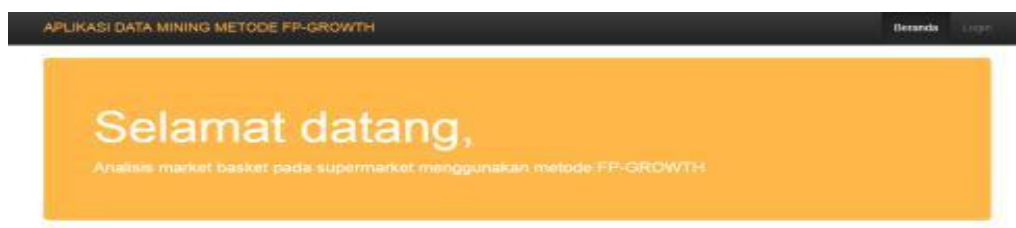

Gambar 1. Tampilan Home 


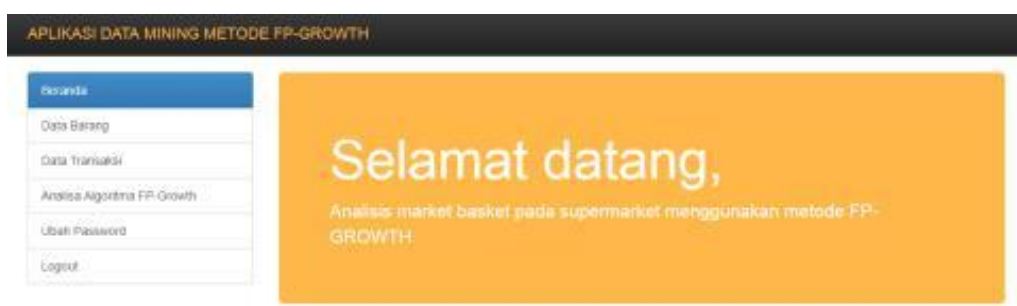

Gambar 2. Tampilan Data Admin



Gambar 3. Tampilan Data Produk

\section{AELKASI DATA MINING METOOE EP.GROWTH}



Gambar 4. Tampilan Analisis Algoritma FP-Growth 

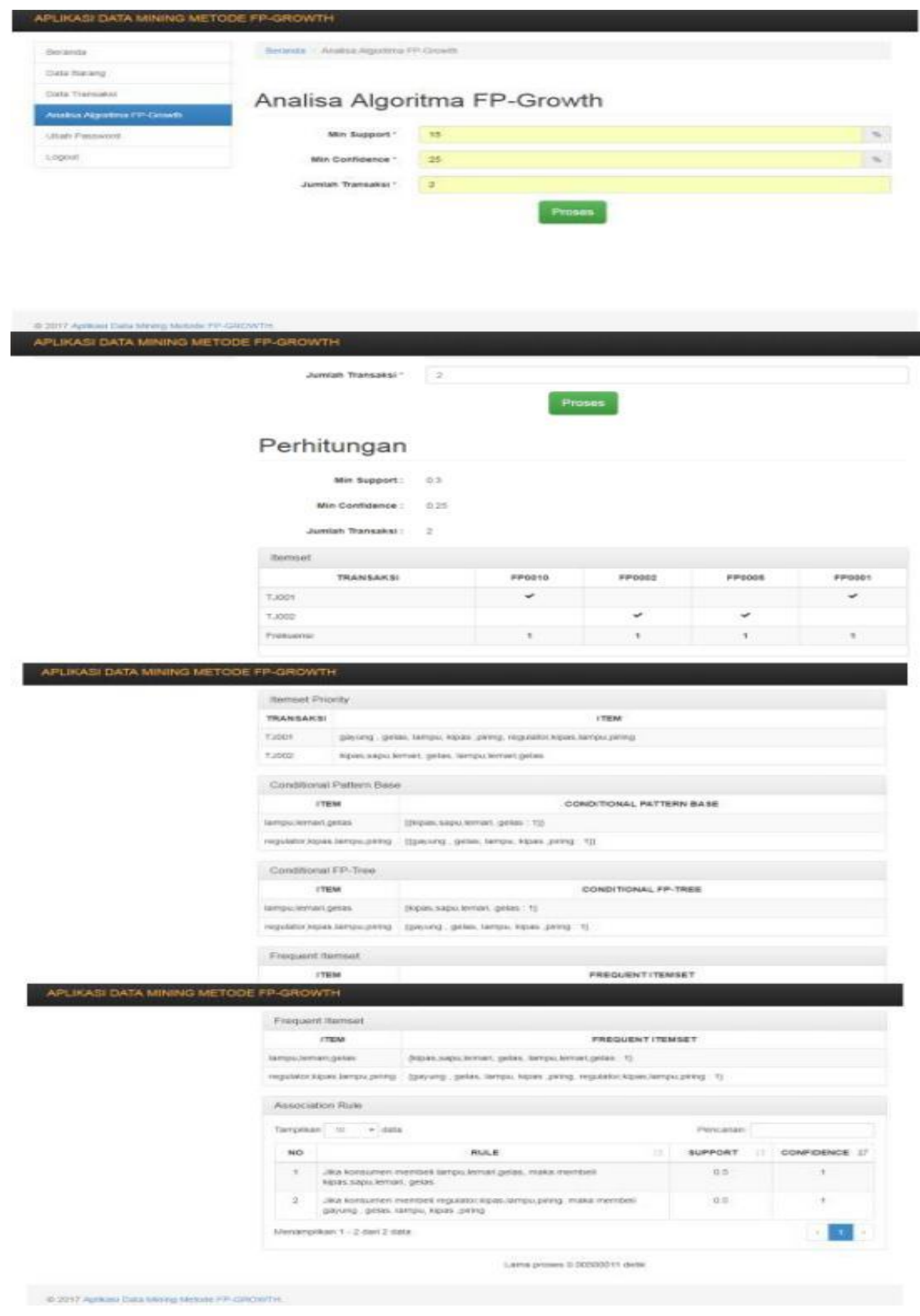

Gambar 5. Hasil Dari Analisa Algoritma FP-Growth

\section{B. PEMBAHASAN}

Proses Data Mining yang diterapkan pada penelitian ini menggunakan metode Market Basket Analysis (Rule Association) dengan Algoritma Apriori. Langkah - langkah dalam penerapan proses Data Mining yaitu pengumpulan data, Inisialisasi data, pembentukan Association Rule, dan pengambilan kesimpulan. 




Gambar 6. Flowchart Sistem Kerja Dalam tahap pencarian frequent

itemset algoritma yang akan digunakan adalah fp-growth. Algoritma ini memiliki dasar pengetahuan mengenai frequent itemset yang telah diketahui sebelumnya untuk memproses informasi lebih lanjut. Dalam algoritma Fp-growth terdapat tiga tahapan penting, namun sebelum masuk pada tahapan untuk mempermudah pembentukan frequent itemset akan dilakukan pengkodean terhadap produk yang terdapat pada data yang sudah siap digunakan untuk proses mining, proses pengkodean ini berdasarkan inisial setiap produk yang terdapat pada transaksi. Berikut adalah pengkodean dari setiap produk dapat dilihat pada tabel dibawah ini:

Tabel 1. Hasil Pengkodean Produk

\begin{tabular}{|l|c|}
\hline \multicolumn{1}{|c|}{ Produk } & Kode Produk \\
\hline Televisi & TV \\
\hline Kulkas & KU \\
\hline Antena TV & ANT \\
\hline K.A Maspion & KM \\
\hline Meja Medium & MM \\
\hline Kipas Angin Mryako & KAM \\
\hline Rice Cooker & RC \\
\hline Jam Dinding & JD \\
\hline Karpet & KRT \\
\hline Rak & RAK \\
\hline Kipas Angin Biasa & KAB \\
\hline Regulator & RGL \\
\hline Lampu & LMP \\
\hline
\end{tabular}

\begin{tabular}{|l|c|}
\cline { 2 - 2 } Produk & Kode Produk \\
\hline Tempat Sampah & TS \\
\hline Vint.co & VC \\
\hline Hanger cjp & HC \\
\hline Ember & EB \\
\hline Sapu ijuk & SI \\
\hline Sikat Wc & SW \\
\hline Gelas & GL \\
\hline Bak Mandi & BM \\
\hline Stok Kontak 4 lubang & SK \\
\hline Kain Pel Dragon & KPD \\
\hline
\end{tabular}

$F p$-tree adalah struktur data yang digunakan oleh algoritma fp-growth dalam penentuan frequent itemset. Kelebihan dari Fp-tree adalah hanya memerlukan dua kali pemindaian data transaksi yang terbukti sangat efisien. Data yang digunakan dalam tahapan ini adalah data penjualan yang telah dilakukan pengkodean pada setiap produknya untuk memudahkan saat pembuatan tree bisa dilihat pada tabel berikut : 
Tabel 2. Penyederhanaan Data Penjualan

\begin{tabular}{|c|l|c|l|}
\hline Kode & \multicolumn{1}{|c|}{ Produk } & Kode & \multicolumn{1}{c|}{ Produk } \\
\hline FP0001 & TV, ANT & FP0077 & RAK, GL \\
\hline FP0012 & TV, MM & FP0078 & KPD, SW \\
\hline FP0016 & KIM, JD & FP0090 & LMP,SK \\
\hline FP0024 & LMP, SK & FP0094 & TS, SI \\
\hline FP0032 & RAK, TS, SI & FP0097 & BM, KPD \\
\hline FP0046 & KAB, KRT & FP0104 & KIM, RC \\
\hline FP0047 & EB, SW, BM & FP0113 & KRT, SI \\
\hline FP0054 & KP, EB & FP0116 & TV, SK \\
\hline FP0055 & LDG, OR, FC & FP0123 & KU, SK \\
\hline FP0056 & LDG, OR, FC, HC & FP0130 & SI, SW, KPD \\
\hline FP0067 & RC, SK & FP0141 & RAK, RC \\
\hline FP0070 & KU, SK & FP0142 & KAB, SK \\
\hline FP0077 & RAK, GL & FP0145 & KIM, MM \\
\hline FP0078 & KPD, SW & FP0149 & EB, SI, SW, KPD \\
\hline
\end{tabular}

Tahap selanjutnya adalah frekuensi kemunculan dari setiap produk dari data transaksi penjualan untuk melihat produk mana saja yang dapat di proses dalam tahap selanjutnya, seperti pada tabel dibawah ini:

Tabel 3. Frekuensi Kemunculan setiap Produk

\begin{tabular}{|l|c|}
\hline Produk & Frekuensi \\
\hline KRT & 2 \\
\hline KAB & 2 \\
\hline LMP & 4 \\
\hline SK & 3 \\
\hline RC & 3 \\
\hline SI & 3 \\
\hline SW & 5 \\
\hline EB & 4 \\
\hline BM & 3 \\
\hline
\end{tabular}

\begin{tabular}{|l|l|}
\hline $\mathrm{HC}$ & 3 \\
\hline $\mathrm{GL}$ & 4 \\
\hline $\mathrm{VC}$ & 2 \\
\hline $\mathrm{KPD}$ & 3 \\
\hline $\mathrm{TS}$ & 2 \\
\hline RGL & 3 \\
\hline KRT & 2 \\
\hline KAB & 3 \\
\hline LMP & 2 \\
\hline
\end{tabular}

Setelah frekuensi dari setiap produk diketahui maka selanjutnya adalah menentukan minimum support, seperti pada tabel berikut ini:

Tabel 4. Penghapusan Data Tidak frequent

\begin{tabular}{|l|c|}
\hline Produk & Frekuensi \\
\hline KRT & 2 \\
\hline KAB & 2 \\
\hline LMP & 4 \\
\hline SK & 3 \\
\hline RC & 3 \\
\hline SI & 3 \\
\hline SW & 5 \\
\hline EB & 4 \\
\hline BM & 3 \\
\hline HC & 3 \\
\hline GL & 4 \\
\hline VC & 2 \\
\hline KPD & 3 \\
\hline TS & 2 \\
\hline RGL & 3 \\
\hline KRT & 2 \\
\hline KAB & 3 \\
\hline LMP & 2 \\
\hline
\end{tabular}

Setelah didapatkan data yang memenuhi minimum support selanjutnya akan dilakukan pengurutan produk berdasarkan frekuensi kemunculan terbanyak dan ditentukan priority untuk setiap produk, seperti pada tabel dibawah ini: 
Tabel 5. Pengurutan Berdasarkan Frekuensi dan Penentuan Priority

\begin{tabular}{|l|c|c|}
\hline Produk & Frekuensi & Priority \\
\hline KRT & 2 & 1 \\
\hline KAB & 2 & 2 \\
\hline LMP & 4 & 3 \\
\hline SK & 3 & 4 \\
\hline RC & 3 & 5 \\
\hline SI & 3 & 6 \\
\hline SW & 5 & 7 \\
\hline EB & 4 & 8 \\
\hline BM & 3 & 9 \\
\hline HC & 3 & 10 \\
\hline GL & 4 & 11 \\
\hline VC & 2 & 12 \\
\hline KPD & 3 & 13 \\
\hline TS & 2 & 14 \\
\hline RGL & 3 & 15 \\
\hline KRT & 2 & 16 \\
\hline KAB & 3 & 17 \\
\hline LMP & 2 & 18 \\
\hline
\end{tabular}

Setelah priority didapatkan, selanjutnya kemunculan produk akan dilakukan pengecekan setiap transaksi untuk diurutkan berdasarkan priority dari masing-masing produk. Berikut adalah hasil dari pengurutan data dapat dilihat pada tabel di bawah ini :

Tabel 6. Hasil Pengurutan Data

\begin{tabular}{|c|c|c|c|}
\hline Kode & Produk(ordered item) & $\begin{array}{l}\text { Kode } \\
\text { FP0054 }\end{array}$ & $\begin{array}{l}\text { Produk(Ordered item) } \\
\text { KP. EB }\end{array}$ \\
\hline FP0001 & TV ANT & $\begin{array}{l}\text { FP0055 } \\
\text { FP0056 }\end{array}$ & IDG, OR, FC \\
\hline & & $\begin{array}{l}\text { FP0036 } \\
\text { FP0067 }\end{array}$ & $\begin{array}{l}\text { LDG, OR, FC, HC } \\
\text { RC. SK }\end{array}$ \\
\hline FP0012 & TV, MM & FP0070 & $\mathrm{KU}, \mathrm{SK}$ \\
\hline FP0016 & $\mathrm{KLM}, \mathrm{JD}$ & $\begin{array}{l}\text { FPO077 } \\
\text { FP0078 }\end{array}$ & $\begin{array}{l}\text { RAK, GL } \\
\text { KPD, SW }\end{array}$ \\
\hline FP0024 & LMP, SK & $\begin{array}{l}\text { FP0090 } \\
\text { FP0094 }\end{array}$ & $\begin{array}{l}\text { LMP,SK } \\
\text { TSS, SI }\end{array}$ \\
\hline FP0032 & RAK. TS, SI & $\begin{array}{l}\text { FP0097 } \\
\text { FPO104 }\end{array}$ & $\frac{\text { BM.KPD }}{\text { KIM, RC }}$ \\
\hline & & FPO113 & KRT, SI \\
\hline FP0046 & $\mathrm{KAB}, \mathrm{KRT}$ & $\begin{array}{l}\text { FP0116 } \\
\text { FP0123 }\end{array}$ & $\begin{array}{l}\text { TV, SK } \\
\text { KU, SK }\end{array}$ \\
\hline FP0047 & $\mathrm{EB}, \mathrm{SW}, \mathrm{BM}$ & $\begin{array}{l}\text { FP0130 } \\
\text { FP0141 }\end{array}$ & $\begin{array}{l}\text { SI, SW, KPD } \\
\text { RAK, RC }\end{array}$ \\
\hline & & $\begin{array}{l}\text { FP0142 } \\
\text { FP0145 } \\
\text { FP0149 }\end{array}$ & \begin{tabular}{|l|} 
KAB, SK \\
KIM \\
FB,
\end{tabular} \\
\hline
\end{tabular}

Setelah mendapatkan data yang sesuai, selanjutnya setiap transaksi penjualan yang terdapat pada tabel 6 akan bangkitkan dengan struktur data $f p$-tree. Berikut adalah penerapan struktur data $f p$-tree : Transaksi dengan kode FP0001: TV, ANT. Diberikan support count 1 dan dua node dengan TV kebutuhan fungsional yang telah sebagai parent dan ANT sebagai child didefinisikan.

Tabel 8. Pengujian Pemilihan Data Transaksi

\begin{tabular}{|c|c|c|c|}
\hline \multicolumn{4}{|c|}{ Kasus dan hasil uji (data normal) } \\
\hline Data masukan & Yang diharapkan & Pengamatan & Kesimpulan \\
\hline $\begin{array}{ll}\text { Data } & \text { transaksi } \\
\text { penjualan.xlsx } & \end{array}$ & $\begin{array}{l}\text { Dapat menampilkan } \\
\text { alamat dari file yang } \\
\text { dipilih }\end{array}$ & $\begin{array}{l}\text { Alamat file muncul } \\
\text { dalam gridview }\end{array}$ & $\begin{array}{l}\text { [V] Diterima } \\
\text { [ ] Ditolak }\end{array}$ \\
\hline \multicolumn{4}{|c|}{ Kasus dan hasil uji (data salah) } \\
\hline Data masukan & Yang diharapkan & Pengamatan & Kesimpulan \\
\hline Alamat file kosong & $\begin{array}{l}\text { Muncul pesan } \\
\text { kesalahan agar } \\
\text { memilih file terlebih } \\
\text { dahulu }\end{array}$ & $\begin{array}{l}\text { Menampilkan pesan } \\
\text { kesalahan untuk } \\
\text { memilh file terlebih } \\
\text { dahulu }\end{array}$ & $\begin{array}{l}\text { [V] Diterima } \\
\text { [ ] Ditolak }\end{array}$ \\
\hline
\end{tabular}




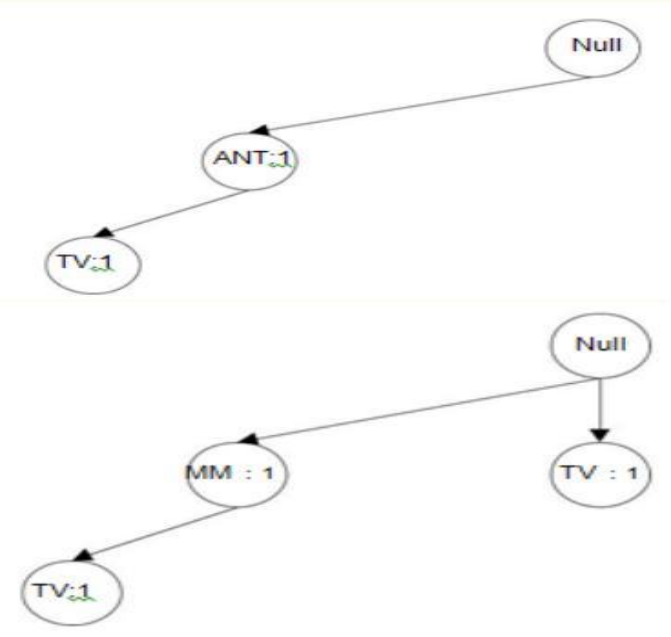

Gambar 7 Struktur data $f p$-tree

Tahap implementasi sistem merupakan tahap untuk mengaplikasikan apa yang telah dirancang pada tahap perancangan sistem berdasarkan hasil analisis sistem. Implementasi sistem ini dilakukan sebagai wujud nyata hasil analisis dan perancangan sistem ke dalam bahasa pemrograman untuk diterapkan pada keadaan yang sesungguhnya. Hasil dari penerapan tersebut diharapkan dapat menjadi sebuah sistem yang siap diuji dan digunakan. Pengujian yang akan dilakukan adalah dengan menggunakan metode white box dan black box serta pengujian beta dengan mewawancarai pengguna yang akan menggunakan perangkat lunak ini.

Tabel 7. Rencana Pengujian

\begin{tabular}{|c|l|l|l|}
\hline$N_{0}$ & \multicolumn{1}{|c|}{ Item Uji } & \multicolumn{1}{|c|}{ Detail Pengujian } & Jenis Uji \\
\hline 1. & Algoritma FP-Growth & Uji Algontma & White box \\
\hline 2. & Pemilihan Data Transaksi & $\begin{array}{l}\text { PengujianvalidasiPemilihanData } \\
\text { Transaksi }\end{array}$ & Black Box \\
\hline 3. & Penyimpananke dalam database & $\begin{array}{l}\text { Penguijan validasi Penyimpananke dalam } \\
\text { database }\end{array}$ & Black Box \\
\hline 4. & Preprocessing Data & Pengujian validasi Preprocessing Data & Black Box \\
\hline 5. & Proses Asosiasi & Pengujian validasi proses asosiasi & Black Box \\
\hline
\end{tabular}

Pengujian black box dilakukan dengan tujuan untuk mengetahui apakah semua fungsi perangkat lunak telah berjalan semestinya sesuai dengan Tabel 8 di bawah ini merupakan scenario pengujian Equivalence Class Partitioning yang dilakukan pada bagian proses asosiasi.

Tabel 9. Pengujian Proses Asosiasi

\begin{tabular}{|c|c|c|c|}
\hline \multicolumn{4}{|c|}{ Kasus dan hasil uji (data normal) } \\
\hline Data masukan & Yang diharapkan & Pengamatan & kesimpulan \\
\hline $\begin{array}{l}\text { Nilai minimum support: } \\
2 \\
\text { Nilai } \\
\text { confidence }: 60 \%\end{array}$ & \begin{tabular}{llr|} 
meghasilkan & aturan & asosiasi \\
yang sesuai & dengan & nilai \\
minimum & support & dan \\
minimum & confidence & dari \\
proses data mining association \\
rule.
\end{tabular} & 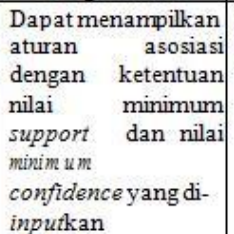 & $\begin{array}{l}\text { [V] Diterima } \\
\text { [ ] Ditolak }\end{array}$ \\
\hline \multicolumn{4}{|c|}{ Kasus dan hasil uji (data salah) } \\
\hline Data masukan & Yang diharapkan & Pengamatan & kesimpulan \\
\hline $\begin{array}{l}\text { Nilai minimum support: } \\
\text { abc } \\
\text { nilai minimum confidence } \\
\text { : abc }\end{array}$ & $\begin{array}{l}\text { Muncul pesan kesalahan agar } \\
\text { menyesuaikan masukan yang } \\
\text { sesuai }\end{array}$ & \begin{tabular}{lr|}
$\begin{array}{l}\text { Menampilkan pesan } \\
\text { kesalahan agar } \\
\text { menyesuaikan }\end{array}$ \\
masukan yang \\
sesuai
\end{tabular} & $\begin{array}{l}\text { [V] Diterima } \\
\text { [ ] Ditolak }\end{array}$ \\
\hline
\end{tabular}




\section{JURNAL PETIR}

Vol. 12, No. 1, Maret 2019, P-ISSN 1978-9262, E-ISSN 2655-5018

Pengujian ini menguji perangkat lunak yang telah dibangun apakah menghasilkan data yang diinginkan dan sesuai dengan hasil penerapan metode association rule dengan algortima FPGrowth. Pengujian ini menggunakan 150 data transaksi penjualan pada tabel 2, setelah dilakukan preprossecing jumlah data menjadi 26 transaksi lalu di generate dengan nilai minimum support ditentukan sebesar 2 dan nilai minimum confidence 60\%. Data hasil preprocessing dapat dilihat pada tabel D-3 dalam lampiran D dan data rule yang dihasilkan dari penerapan metode association rule.

\section{KESIMPULAN DAN SARAN}

Berdasarkan pada hasil perancangan, implementasi, dan pengujian terhadap "Implementasi Data Mining Pada Penjualan Produk Di Toko Cahaya Setya Menggunakan AlgoritmaFp-Growth", dapat disimpulkan sebagi berikut:

1. Bahwa semakin kecil nilai minimum support maka akan semakin banyak aturan asosiasi yang dihasilkan, dan sebaliknya semakin besar nilai minimum support maka akan semakin sedikit aturan asosiasi yang dihasilkan. Semakin kecil nilai minimum confidence, kemungkinan nilai kepastian aturan asosiasi yang dihasilkan akan semakin banyak dan semakin besar nilai minimum confidence maka akan semakin sedikit aturan asosiasi yang dihasilkan.

2. Metode Association Rule dengan menggunakan Algoritma FP-Growth yang dibangun melalui Aplikasi dapat membantu Toko Cahaya Setya

3. Diharapkan penelitian ini dapat menjadi referensi bagi penelitian selanjutnya dengan mengembangkan aplikasi dengan menggunakan algoritma yang lainnya.

\section{DAFTAR PUSTAKA}

[1] Erwin. (2015). Analisis Market Basket dengan Algoritma Apriori \& FP-Growth. Jurnal Generic No.26-30.

[2] Jiawei, H., Kamber, M. (2015). Data Mining Concepts and Techniques, Morgan Kaufmann Publishers.

[3] Fajrin, Alfannisa Annurullah dan Algifanri Maulana. (2018). Penerapan Data Mining Untuk Analisis Pola Pembelian Konsumen Dengan Algoritma Fp-Growth Pada Data Transaksi Penjualan Spare Part Motor.Jurnal Ilmu Komputer (KLIK) Teknik Informatika, Universitas Putera Batam Volume 05, No.01 Februari 2018.

[4] Firdaus, Diky. 2017. Penggunaan Data Mining dalam Kegiatan Sistem Pembelajaran Berbantuan Komputer. Jurnal Format Volume 6 Nomor 2 Tahun 2017

[5] David Samuel, penerapan Stuktur FP-Tree dan Algoritma FP-Growth dalam Optimasi Penentuan FrequentItemset, Institut Teknologi Bandung, Vol. 1, 2008.

[6] Saad, A. dan Alghamdi, A., (2016). Efficient Implementation of FP Growth Algorithm-Data Mining on Medical Data. 11(12), pp.7-16.

[7] Cahyana, Nur Heri et all. (2017), Aplikasi Penerimaan Siswa Baru Berbasis WEB (SMK Negeri 3 Yogyakarta). TELEMATIKA Vol. 10, No. 1, JULI 2013: 1 - 8.

[8] Sijabat, ALimancon,(2015). Penerapan data mining untuk pengolahan data siswa dengan menggunakan metode decision tree. Jurnal Informasi dan teknologi Ilmiah Volume 5 No. 3 ISSN:2339-210x

[9] Ellis, software Engineering, SIGSoft Software Engineering Notes Vo. 32 (2015)

[10] Web Dalam Perkembangan and Winda Febriani Kusuma (2015). Pengembangan halaman web, menggunakan XML Dalam PErkembangan WEB 2.0, Jurnal Teknik Informatika 6 (2):8 